\title{
Recognizing the significance of a Viking fortification in its landscape
}

\author{
C. Canzonieri \\ Department of Architecture and Engineering, Kore University, Italy
}

\begin{abstract}
Through the analysis of a case study the paper discusses how a landscape approach can bring instruments for the identification of a hidden monumentality, linking landscape and history for the identity of the territory. The case shows that measures aimed at highlighting an archaeological element can have the effect of creating a new awareness not only of the monument once forgotten, but also of the rediscovered surrounding landscape. The context approach brings a reciprocal advantage both to the monument and to the landscape, and promotes a renewed contemporary cultural use.
\end{abstract}

Keywords: archaeological landscape reading, fortified heritage, identity awareness and cultural tourism.

\section{Introduction}

In the countryside at the base of the Jutland peninsula, in a plain ordered by the linear geometry of the hedgerows defining the fields, a medieval archeological element is at the same time history and landscape. In this landscape environment, linear and flat, an element of unexpected dimensions stands out, which impresses in the landscape the mark of relevant historic events.

A presence central to the culture of two countries, which becomes an opportunity for the design of a landscape of large breadth, within which natural elements intertwine with components of a military fortification. The scale of its linear extension, about $30 \mathrm{Km}$, and of its volume, a prism of $20 \mathrm{~m}$ base by 3 to $8 \mathrm{~m}$ high, bestow on it a role not only of archaeological object, but also of characterizing landscape structure at a territorial scale.

The Carta Marina, map published in Venice in 1539 by the Swedish ecclesiastic Olao Magno, shows a continuous fortification between the opposite 


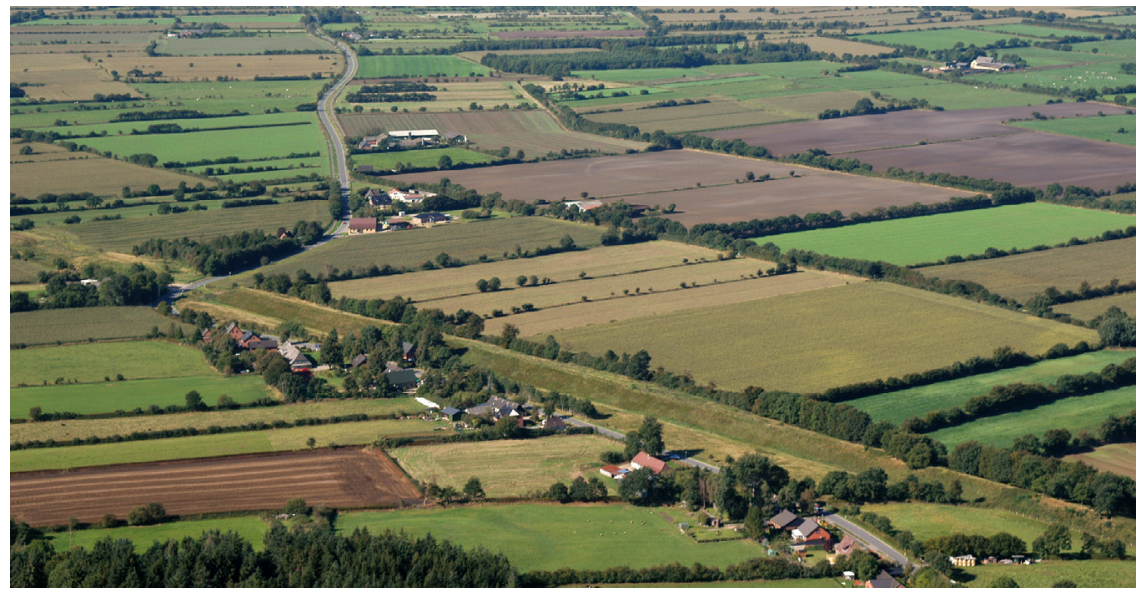

Figure 1: The Danewerk in its current landscape.
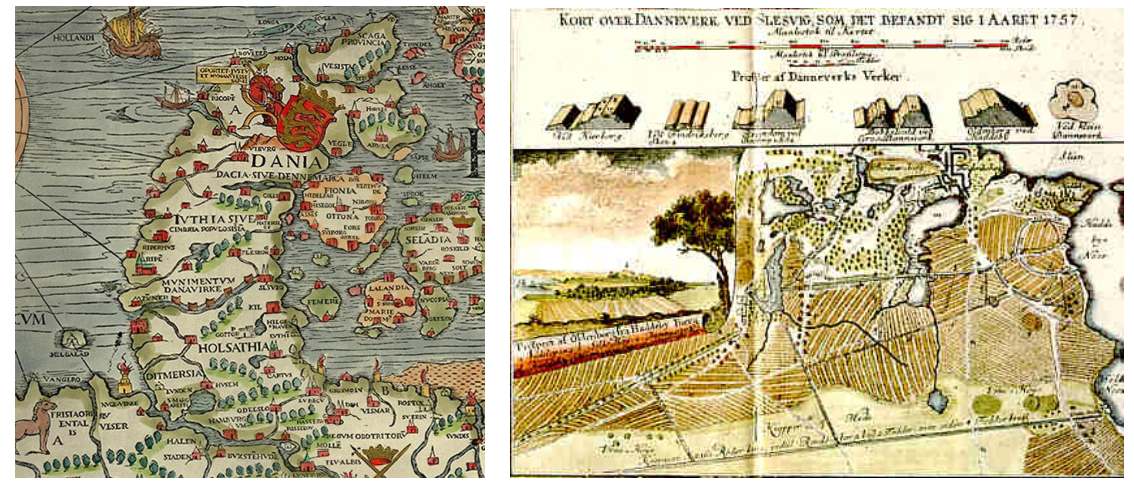

Figure 2: The Danewerk in the Carta Marina of 1539 and in the Map of Pontopiddans of 1757.

coasts of the Danish peninsula. The Map of Pontopiddans of 1757 shows the landscape around the fortification and some details with the different shapes, with a trench or without, that the fortification would take on along its length.

During the Middle Age the Viking Kings, in order to protect their dominion from possible invasions coming from south by Saxons and Franks, built the fortification in different phases. The first ones were simple earthen volumes. Above these later on palisades were built whose remnants dendrochronological analysis date back to $737 \mathrm{AC}$. The landscape was part of the whole as the monument included in its alignment elements of difficult access as wetlands and river courses. In the last phase, at the end of the 12th century, Waldemar the Great improved it with $7 \mathrm{~m}$ high brickwork and a trench along the majority of its length. The Danewerk has continued being in use until the 13th century before 
being abandoned [1]. In the 15 th century it fell into decay, it was strengthened by the Danes in 1848 and abandoned after the war of 1864. Excavation of the earthwork was then established in 1900.

\section{Value of the structure}

The combination of these parts, collectively called Danewerk, beside its archaeological value and landscape relevance, also takes on a meaning of identity for the Danish communities living in these territories, which are today German. The new reading and enhancement of the Danewerk becomes an instrument of promotion for the region, putting forward a sense not of separation anymore, but of union between the Danish and German communities. Heritage sites of the past are given meaning by the relationship with people in the present [2]. The present meaning of places might be more significant to today's inhabitants than past historical meanings [3]. In a phenomenology of landscape approach [4], as the materiality of the monument is not only the sum of its disconnected parts, the surrounding landscape is a founding component of its wholeness and significance. A phenomenology of the monument will not present a uniform experience [5]. The system, rather than an object locked in time, can offer different readings of varying military strategies or historical situations [6]. By perceiving archaeological space, each generation revives and reinterprets its history [7]. Similarly to what is described by Nesbitt and Tolia-Kelly about Hadrian's Wall, the Danewerk, once a landscape of power and exclusion, is now moving towards a landscape of leisure, imbued with meaning. The marking of the Danewerk as part of the national cultural heritage also shifts the meaning of the surrounding landscape.

\section{Characters of the actions}

The Danewerk was used in different times and modifications occurred both within the monument and within the landscape elements related to it. Several levels of actions are necessary:

1. at the territorial scale, in order to place the Danewerk at the center of an cultural system, strengthening relationships with nearby historic sites to root the Danewerk in a larger context;

2. at the scale of the fortification system, to underline the monumental nature of the continuity of the artifact, to point to attention the non randomness, but rather the real identity as a monument that belongs to a stretch of landform which in some sections might not be recognized as such, to mend visually occasional interruption;

3. at the detail scale appropriate actions are necessary to reconcile accessibility and integrity of the monument.

While for archaeological remnants of buildings the more frequent reuse entails physical occupation of the monument, for this type of structure reuse means 
mainly redefining its perception and acquiring its image in the individual and collective experience. While for the first the new interventions are primarily focused on the building itself or on its immediate surroundings, the latter requires above all a multiplicity of actions external to the monument itself.

\subsection{The planning level}

The first point to affirm is the acknowledgment of the value of each individual part for the purpose of defining the value of the entire system. The planning level is where possible damages due to shortsighted local choices are to be prevented. In order to keep the entirety of the system, which crosses different communities a layer of planning, a sort of overlay zone, has to oversee land use and infrastructure adjacent to the fortification. Priority to the legibility of the monument has to inform decision in case of conflict. It is necessary that modifications due to anthropic necessities of development be evaluated with different alternatives in order to be compatible with the integrity of perception of the Danewerk. As an example, in the case of the figure, the overlapping of infrastructures indicated in the oval creates an interruption both physical and perceptual of $200 \mathrm{~m}$, distance long enough to obstruct inter-visibility between the parts and therefore perception of continuity.

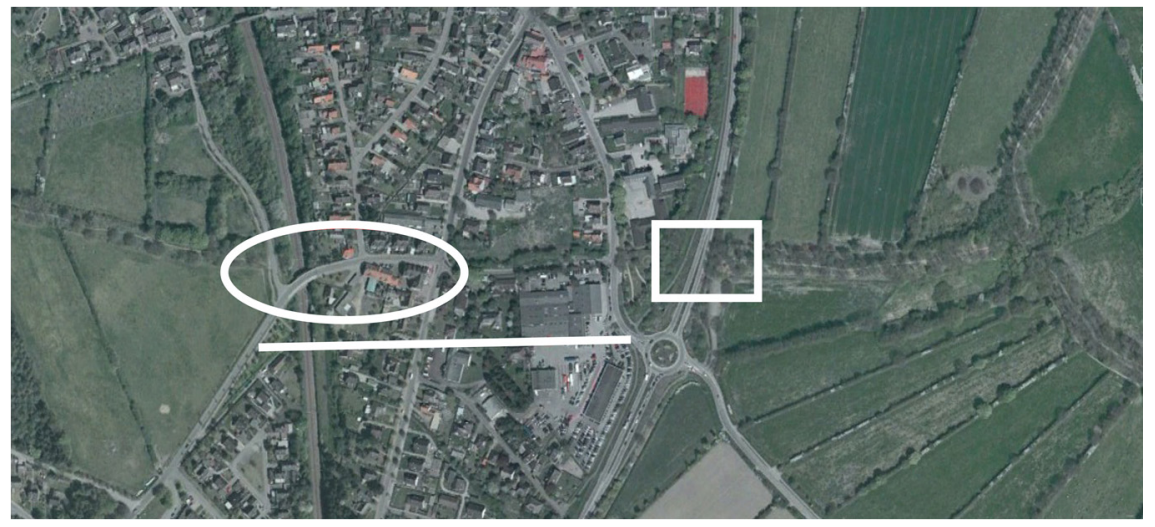

Figure 3: (a) Possible alternative alignment of the road (line); (b) area for site redesign in the tract where the fortification has disappeared (oval); (c) suggested underpass (square).

Here a coordinated planning could have instead placed the bridge and the traffic road on the alignment of the line marked in the figure, allowing the possibility of a redesign in the area of the missing link indicated in the oval, according to the aims of a perceptual continuity and of a pedestrian connection towards the western side of the town. Planning the highway to prioritize the earthwork would have called for an underpass at the intersection with the earthwork so allow continuity along the monument alignment. 
A careful planning could ensure both the optimal visibility of the fortification and the retention within its surroundings of open spaces as protection of visual relationships. Only recently the Management Plan Haitabu \& Danewirke of 2013 [8] declares as a goal to make the development of the community and its surroundings compatible with the protection of the fortification. The document, created from the pressure to define which could be the development areas, given the evidence of increasing transformations in the landscape, is a reference point for the prevention of the decrease of the value of the monument, but it needs a more detailed definition in prescribing specific actions.

\subsection{The design level}

The appreciation of a monument of this kind takes place through its perception while experiencing the landscape context. The enhancement of the earthen fortification cannot be addressed only to the artifact but has to include the landscape context, which was fully part of the defense system [9]. The design of the landscape therefore becomes the mean for the reuse of the archaeological complex. The construction of the Danewerk had deliberately taken in elements of the landscape as lakes and wetlands to include them as obstacles between tracts of fortification. The draining of them has obscured these relationships, and new design could make them perceivable again.

To observe the changes we refer to the map of Neynabers and Hemsens, 1761, still showing lakes and marshland and the fortification in its landscape context. In order to compare it with contemporary landscape changes the map has been overlaid to the aerial image of the same area in Google Earth, and the overlap is shown here at different level of transparency to better appreciate the correspondence between map and contemporary image. The comparison shows both strong permanence of alignments as roads and fields' borders, and also shows clearly the location of lakes and wetlands now drained.

Restoring the presence of water would give back meaning to the fortress, reinforce the experience of the setting and the connection with the past history. The continuity of a path could be made possible with the highway going through an underpass. In other areas gaps in the earthwork could be marked on the ground, the edge of wetlands could be suggested with the establishment of wet meadows and appropriate vegetation. An agri-archaeological park could be able to redefine the different ecosystems that the earthwork goes through, moraines, moorlands, and riverside meadows. In the vicinity of the artifact, and where there would be no conflict with visibility, different natural areas could be established, to represent elements of mature forest, areas with sparse trees with the presence of sheep and oxen, areas to recover traditional agriculture or which, in the vicinity of settlements, accommodate urban gardens or educational projects. 


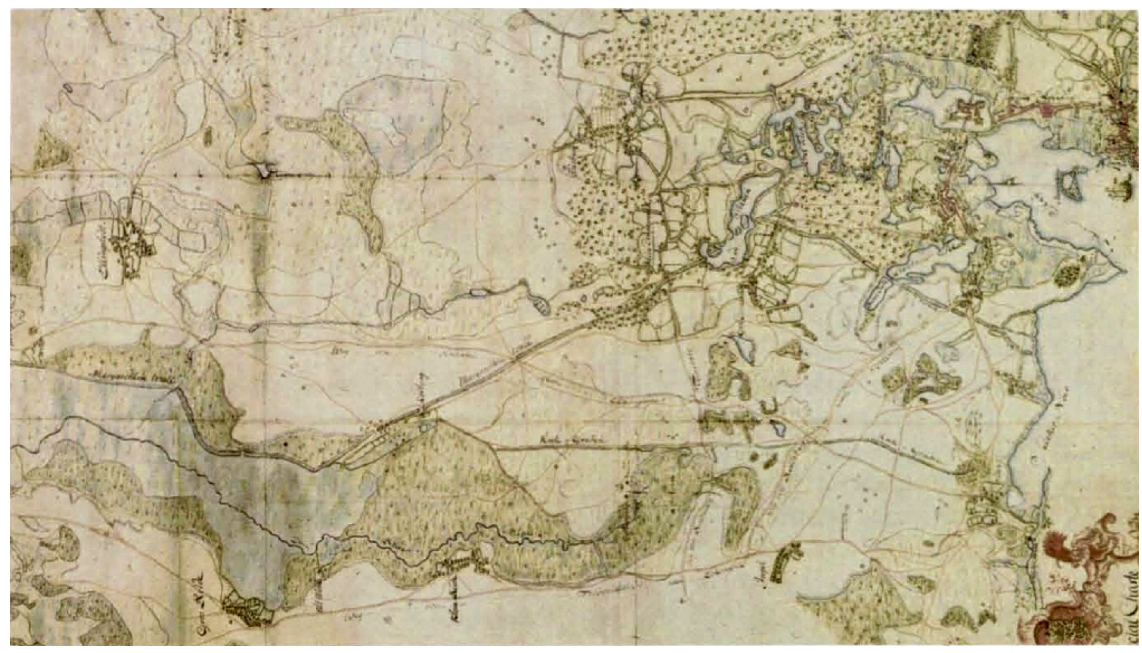

Figure 4: Map of Neynabers and Hemsens, 1761, still showing lakes and marshland, Habitabu on the middle right of the map.
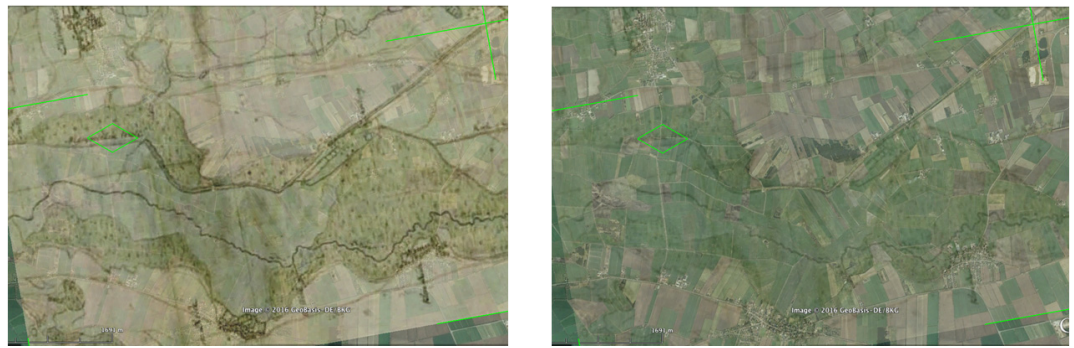

Figure 5: Marshland and fortification in the map and in the current state.
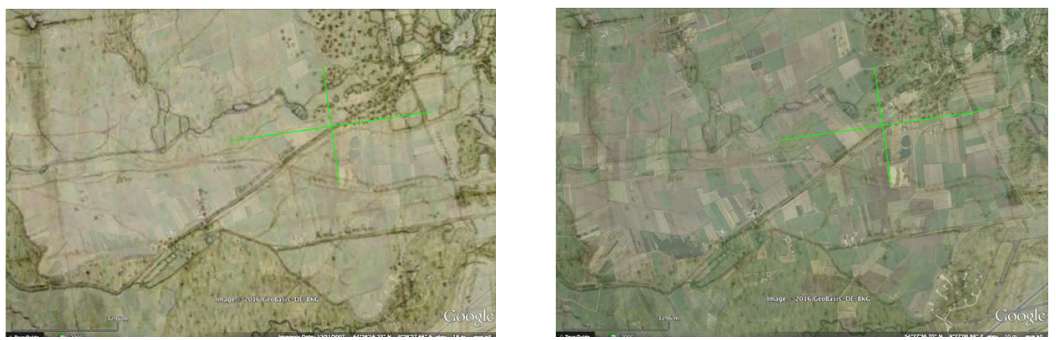

Figure 6: The continuous line of fortification in the map and in the current state. 

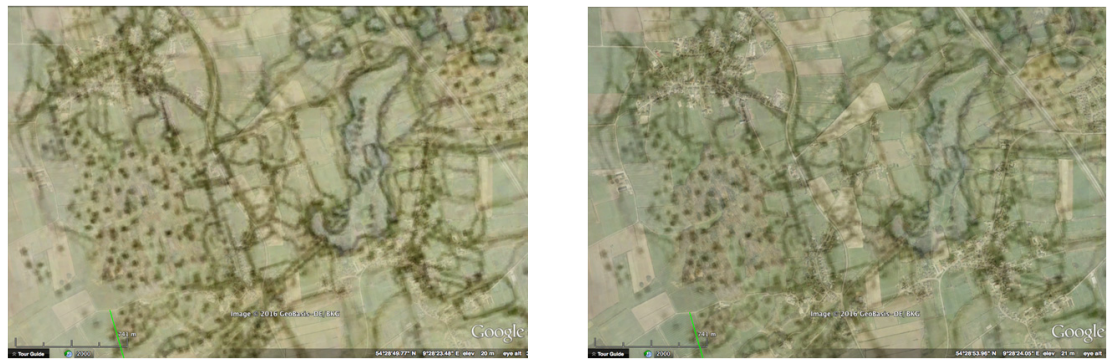

Figure 7: Danewerk lake and fortification in the map and in the current state.

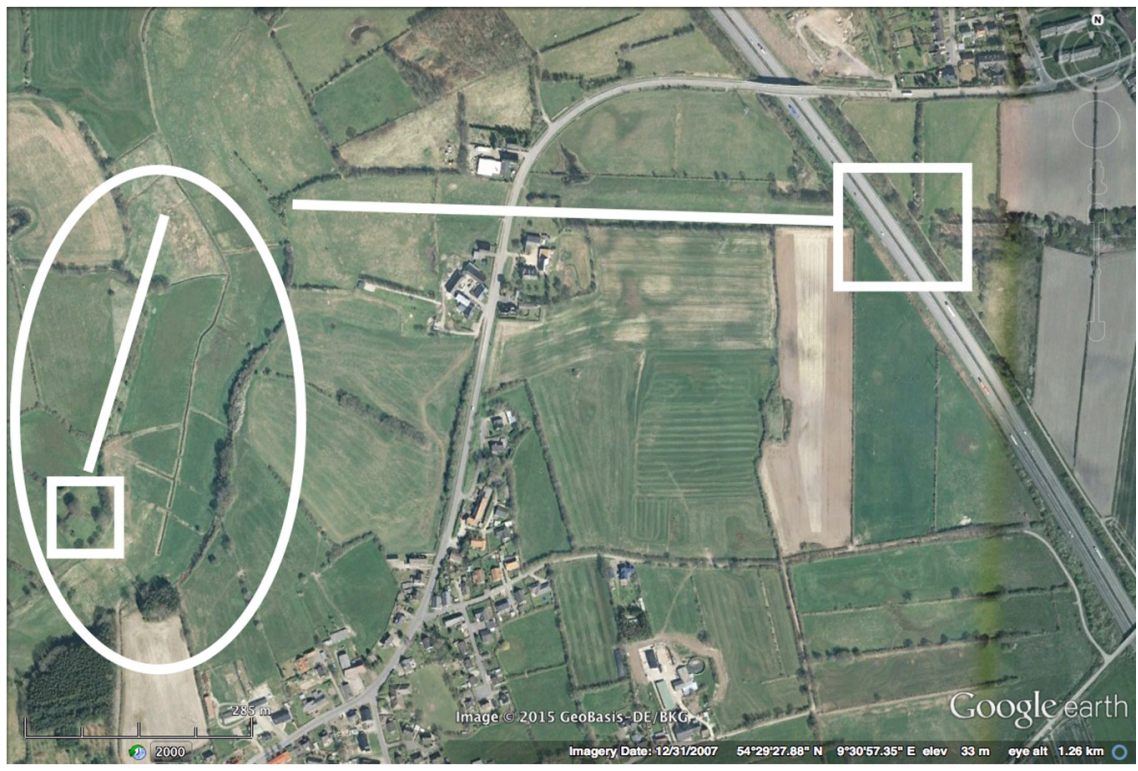

Figure 8: The defense earthwork appears along the lines. Inside the oval the drained lake and "the fortress". Inside the square a critical interruption.

\subsection{The detail level}

The issue of the missing sections along the fortification could become an opportunity for solutions both as permanent actions and ephemeral events in order to allow the reading of the continuity of the artifact, visually mending interruptions, showing sometimes the alignment with different materials, or suggesting the volume, using a contemporary artistic vocabulary, experienced as participatory activity, seasonal or random. 
The vegetation covering the terrain could be thought of in its function of holding the soil, yet diversity from the adjacent vegetation could also be envisioned in different seasons or different tracts where differences could be helpful to enhance perception.

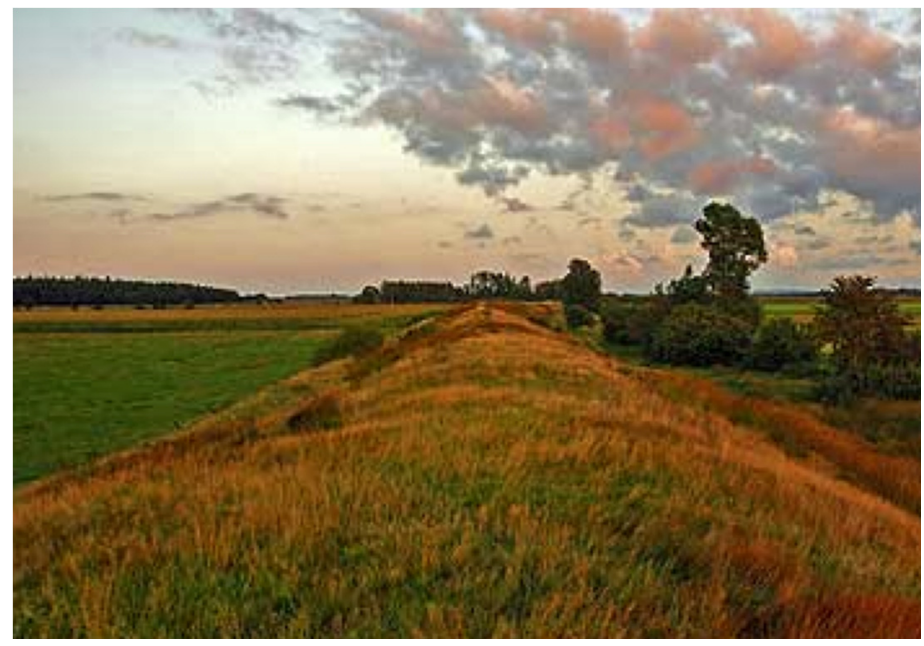

Figure 9: Seasonal chromatic differences between the vegetation of the earthwork and the vegetation of the surrounding fields, as a suggestion for intentional diversity applications.

\section{Conclusion}

Through a landscape sensibility it is necessary to direct around the monument the requalification of the surrounding landscape and adjacent urban edges giving people spaces for enhanced experience and a new awareness of the presence of a monument no longer forgotten. It is therefore evident the relevance of coordinated plans and designs along the entire historic line of the Danewerk, both where traces still remain, in order to underline their value, and also where these have been deleted in order to recovery their memory. A planning that, by overlay zoning, brings together different administrations in a shared planning of a land of variable width, depending on the visibility and the adjacent landscape elements, is necessary to the retention of a continuous sign of such archaeological feature in the territory. From the awareness of the monumentality of the earthwork the recovery of the surrounding territory will begin for a compatible use. A closer link with the monument could be facilitated by designs aimed to underline the presence of the structure and its diversity from the context of other elements of the rural landscape, for a reuse intended manly as enhancement of the perceptual experience, supported by direct contact in chosen points. 


\section{References}

[1] Andersen, H. H. Danevirke. Jysk Arkæologisk Selskab København: i kommission hos Gyldengal, 1976

[2] Russell L. Remembering places never visited: Connections and context in imagined and imaginary landscapes. International Journal of Historical Archaeology 16(2), 2012

[3] David, B., Lamb, L., Delannoy, J.-J., et al. Poromoi Tamu and the case of the drowning village: History, lost places and the stories we tell. International Journal of Historical Archaeology 16(2), 2012

[4] Tilley, C. A Phenomenology of Landscape: Places, Paths and Monuments. 1994

[5] Witcher, R., Tolia-Kelly, D., Hingley, R., Archaeologies of landscape. Excavating the materialities of Hadrian Wall. Journal of material culture. Vol. 15(1) 2010

[6] Dobat, A. S. An investigation into military and socio-political organization in South Scandinavia (c AD 700 to 1100), Medieval Archeology, 52,1 2008

[7] Nesbitt, C., Tolia-Kelly, D. Hadrian's Wall. Embodied archaeologies of the linear monument. Journal of Social Archaeology. Vol. 9(3), 2009

[8] Archäologisches Landesamt Schleswig-Holstein. Management Plan Haithabu \& Danevirke, 2013

[9] Van der Anker, H., Jungerius, P. D. Landscape settings as part of earth wall systems for defence. Geophysical Research Abstracts Vol. 15, EGU20135982,2013 